International Journal of Automotive and Mechanical Engineering ISSN: 2229-8649 (Print); ISSN: 2180-1606 (Online);

Volume 14, Issue 1 pp. 3985-3997 March 2017

CUniversiti Malaysia Pahang Publishing

DOI: https://doi.org/10.15282/ijame.14.1.2017.13.0323

\title{
Evaluation of alternative drive systems based on driving patterns comparing Germany, China and Malaysia
}

\author{
M. Schüller ${ }^{a}$, S. Tewiele ${ }^{b}$, T. Bruckmann ${ }^{c}$ and D. Schramm ${ }^{d}$ \\ Chair of Mechatronics, Faculty of Engineering, \\ University of Duisburg-Essen, 47057 Duisburg, Germany \\ Email: ${ }^{a}$ mira.schueller@uni-due.de, bsarah.tewiele@uni-due.de, \\ ctobias.bruckmann@uni-due.de, dieter.schramm@uni-due.de
}

\begin{abstract}
Requirements to mobility are changing worldwide due to a focus on environment and resource protection and a simultaneous increase of mobility needs. Accordingly, the focus in automotive development shifts to the use of alternative energies for vehicle propulsions in order to reduce emissions. The amount of emission reduction by using alternative drive systems depends on marginal conditions, such as the energy mix structure, climate conditions and the vehicle's usage profile. The individual usage profile contains characteristic values such as the number of trips, trip duration and length, as well as the velocity distribution. These characteristic data are individual for each user and differ from the values derived through test cycles such as e.g. the NEDC or the JC08. Accordingly, for the current market analysis and future trends prediction, different user profiles have to be considered and analysed. Within this paper, real world driving data recorded within the German project RuhrautoE will be analysed. The focus lies on evaluation criteria that differentiate between countries due to local framework conditions. In this context, the costs and emissions of different propulsion systems are compared between Germany and China. Afterwards an outlook on Malaysia is given for these criteria. Hitherto, such an approach is rarely considered for Malaysia. Conventional and alternative fuel vehicles as well as electrified vehicles (EV) are compared within this paper. All car models considered are based on real vehicle series to ensure a valid common basis. As expected, the consumptions of all analysed propulsion systems are higher for real driving data than for the NEDC. Then the consumption costs of the electric vehicle are the lowest in Germany and China, but not in Malaysia, where a gas driven vehicle (LPG) achieves the best results. Though, while electric cars can reduce well-to-wheel emissions by $82 \%$ in Germany, there is no reduction possible in China as long as the fossil proportion during the generation of electricity is not reduced. However, EV can reduce the local emission in high traffic areas. According to our estimation, EV are not profitable in all considered countries due to the Total Cost of Ownership.
\end{abstract}

Keywords: Green energy technology; electric mobility; driving pattern; total cost of ownership; China; Malaysia; drive train.

\section{INTRODUCTION}

The global population growth and the increasing urbanisation lead to a high demand for mobility. As a result, the increasing energy consumption, rising $\mathrm{CO}_{2}$ emissions and limited fossil resources create global challenges to sustainable mobility. Driven by the 
political, social and technical megatrends, sustainable and energy efficient drive solutions dominate current vehicle development strategies [1]. In addition to a further optimisation of conventional drives in terms of energy efficiency, alternative and electrical drive systems can make a high contribution to emission reduction [2]. As shown in several studies, the energy consumption of a vehicle is affected by a wide range of factors covering i.e. the road type (urban, highway) or the driving and usage behaviour [3-7]. These user individual factors are represented in real usage profiles. For vehicle development, as well as current and future market analysis, real usage profiles have to be used in order to gain realistic consumption data, which differ from the data derived through test cycles like the New European Driving Cycle (NEDC) [8]. For an evaluation of drive systems not only the consumption but particularly the resulting emissions and cost data play an important role. Thus, a realistic evaluation of different drive systems not only requires real usage profiles but also a holistic approach considering local framework conditions such as cost structure or energy supply.

A high barrier for the purchase of electrified vehicles is constituted by the high purchase costs. In contrast, the operating costs are lower due to low energy prices. A common method to calculate the overall costs within a certain period including the cost change over time from the user's perspective are the Total Costs of Ownership (TCO) models. There is a high range of factors affecting the TCO. A very detailed TCO model is proposed by Al-Alawi and Bradley [9] aiming to cover all possible influencing factors and their change over time. However, the used cost values represent the US-market. Another TCO calculation is introduced by the German national platform for electric mobility [10]. Here, three factors are considered: purchase costs, value loss and maintenance costs. The vehicle purchase costs are calculated by the vehicle basic costs and specific powertrain components. Hou [11] introduces a TCO model for China to optimise battery size for Plug-in hybrid electric vehicles. The TCO model includes battery, fuel, electricity, and salvage costs. Due to different local framework conditions such as energy prices, the TCO as well as emissions differ between countries. Research on a comparison of TCO and emission values for different countries is rare.

The range of vehicle models considered in this paper cover conventional and alternative fuel vehicles such as gasoline, Diesel, CNG (Compressed Natural Gas) and LPG (Liquefied Petroleum Gas), as well as battery electric and plug-in hybrid electric vehicles for all vehicle classes. Within this analysis, the mentioned propulsion systems are compared to each other based on real usage profiles. The effects of different charging scenarios and various battery sizes on suitability and efficiency are considered and discussed in [12]. This study aims to conduct a cross-national evaluation of these vehicle drives, wherefore the relevant parameters will be configured due to the local conditions of Germany, China and Malaysia.

\section{METHODS AND MATERIALS}

\section{Dataset}

In this paper, driving data based on GPS and collected in the Rhine-Ruhr region in Germany is considered, whereas this region is representative for a major conurbation in Germany. In total, 40,000 km of travelled distance is covered. During more than 3,300 trips on board data, loggers recorded e.g. the velocity as well as the GPS position (longitude, latitude, altitude) of the vehicle every second. The used vehicles are both electric and hybrid cars provided to private and commercial users through a car sharing system. Considering that plenty of different people drive vehicles in car sharing, the 
average of different driving styles and their driving profiles can be considered. It is assumed as a hypothesis that the collected dataset is comparable to the driving data of Chinese and Malaysian conurbations. Presently, projects are initiated to gather real driving data in China and Malaysia. The results of these data acquisition tasks are foreseen for subsequent publication.

\section{Vehicle Propulsion Systems}

In this paper, conventional and alternative fuel vehicles, as well as electrified vehicles (EV), are compared. To ensure a valid common basis for the comparison of vehicles with different drive trains, all car models considered are based on real vehicle series, respectively. However, as there is no real vehicle series with all mentioned power trains on the market, partly fictitious vehicles are used. That means that the vehicle parameters stay the same except for the powertrain. To realise this concept, a mass model is used, which evaluates the additional weight resulting through an integration of alternative drive trains based on a conversion design model as well as the needed battery size for a certain range. The reference car within this paper belongs to the subcompact category. The used vehicle models cover in detail models of internal combustion engine vehicles (ICEV) with a gasoline, diesel, CNG (Compressed Natural Gas) as well as a LPG (Liquefied Petroleum Gas) engine. Furthermore, models for a battery electric vehicle (BEV) with centre drive and a battery of $19 \mathrm{kWh}$ and a serial plug-in hybrid electric vehicle (PHEV) with a battery of $5 \mathrm{kWh}$ are used. A detailed description of the simulation models and the weight model, as well as an analysis of the consequences due to the different battery sizes of a PHEV is given in $[2,12-14]$.

\section{Evaluation Criteria}

The vehicle drives are evaluated based on their consumptions and emissions as well as on the Total Cost of Ownership (TCO). It is also assumed that the electric vehicle can realise all the trips independently of the battery capacity and that the battery of the electrified vehicle is always fully charged at the start of a trip.

\section{Consumption}

In combination with the recorded driving data, the simulation models of the different propulsion systems enable the generation of realistic energy consumptions. Specifically, this means that not the average, but the actual fuel and electricity consumption for each trip will be considered in the comparison. Thus, the possibility is covered that plug-in hybrid electric vehicles can realise trips for example under purely electric power. Because of the different physical units, the comparison of consumptions is based on the costs. The considered costs per unit of energy are shown in Table 1. It is distinctive, that there is a factor of about 1.5 between the German and Chinese prices for fuel. The costs for electricity in Germany are more than twice as high as in China.

Table 1. Cost per unit of energy for Germany [15-17] and China [18-21]

\begin{tabular}{llll}
\hline & Germany & & \multicolumn{1}{l}{ China } \\
\hline Diesel & $1.350 € / 1$ & $0.900 € / 1$ & $6.110 \mathrm{CNY} / \mathrm{l}$ \\
Gasoline & $1.493 € / 1$ & $1.010 € / 1$ & $6.880 \mathrm{CNY} / 1$ \\
LPG & $0.634 € / 1$ & $0.470 € / 1$ & $3.196 \mathrm{CNY} / 1$ \\
CNG & $1.040 € / \mathrm{kg}$ & $0.640 € / \mathrm{kg}$ & $4.340 \mathrm{CNY} / \mathrm{kg}$ \\
Electricity & $0.292 € / \mathrm{kWh}$ & $0.120 € / \mathrm{kWh}$ & $0.810 \mathrm{CNY} / \mathrm{kWh}$ \\
\hline
\end{tabular}




\section{Emissions}

The legislation all over the world will focus even more on the emission of vehicles in the future. Thus, greenhouse gas (GHG) emissions play an important role in comparing vehicle drives. For this purpose, it is essential to consider both the direct emission at the vehicle (tank-to-wheel, TTW), as well as the indirect emission of the energy provision (well-to-tank, WTT). The addition of both yields the well-to-wheel (WTW) emission. According to the definitions in the Kyoto Protocol, GHG emissions are measured in $\mathrm{CO}_{2}-$ equivalents $\left(\mathrm{CO}_{2} \mathrm{e}\right)$. Table 2 contains the regarded factors for Germany and China. Sources for China are data derived by [22-24], which were converted into comparable units.

Table 2. Well-to-wheel emission factors for Germany [25, 26] and China [22-24].

\begin{tabular}{llll}
\hline & & Germany & China \\
\hline Diesel & {$\left[\mathrm{kgCO}_{2} \mathrm{e} / \mathrm{l}\right]$} & 3.150 & 3.635 \\
Gasoline & {$\left[\mathrm{kgCO}_{2} \mathrm{e} / \mathrm{l}\right]$} & 2.800 & 3.109 \\
$\mathrm{LPG}$ & {$\left[\mathrm{kgCO}_{2} \mathrm{e} / \mathrm{l}\right]$} & 1.900 & 2.002 \\
$\mathrm{CNG}$ & {$\left[\mathrm{kgCO}_{2} \mathrm{e} / \mathrm{kg}\right]$} & 3.070 & 4.234 \\
Electricity & {$\left[\mathrm{kgCO}_{2} \mathrm{e} / \mathrm{kWh}\right]$} & 0.593 (electricity mix) & 0.982 (electricity mix) \\
& & 0.136 (green power) & \\
\hline
\end{tabular}

As shown in Table 2, the $\mathrm{CO}_{2}$-equivalents of Germany are in any case lower than the Chinese factors. The main reason is that the electricity in China is generated mostly from fossil fuels reaching a proportion of $78 \%$, while $3 \%$ belongs to renewable energy sources. Studies regarding China's future power source structure indicate that coal will continue to dominate the electricity mix in the near and mid-term future [27]. Other factors are the plant and transmission efficiency. Since electricity is often transmitted over great distances to urban customers, an additional loss of electricity due to long distance transmission reaches 6.5\% [27] and is slightly higher than in Germany, where the transmission energy loss is 4\% [28]. For Germany, the table gives two factors for electricity [25]. On the one hand, for the German electricity mix, where less than $22 \%$ belongs to renewable energy sources and on the other hand for pure green power, where it is assumed that all electric energy comes from renewable sources. The factor for the German electricity mix is more than four times higher than the $\mathrm{CO}_{2}$-equivalent for pure green power.

\section{Total Cost of Ownership}

In order to evaluate the overall costs arising for a customer within a certain period of time, a Total Cost of Ownership (TCO) Model is implemented. Similar to [29, 30] the parameters cover the vehicle purchase costs, variable costs, fixed costs and consumption costs shown in Figure 1. Differences due to country specific cost structures are considered and significant parameters are marked grey in Figure 1.

$$
r_{v}=a * P_{\text {purchase }} *\left(1-b \frac{m}{15000[\mathrm{~km}]}\right)^{p}
$$

Eq. (1) contains the purchase price $P_{\text {purchase }}$, the yearly mileage $m$ in $\mathrm{km}$, the holding period $p$ as well as the factors $a$ and $b$, which differ between the drivetrain technologies and vehicle size and are shown in Tab. 3 for sub- and compact vehicles. 
Table 3. Residual value factors for (sub-) compact vehicles [29].

\begin{tabular}{lll}
\hline Drivetrain & $a$ & $b$ \\
\hline ICEV (Gasoline) & 0.7185 & 0.0955 \\
ICEV (Diesel) & 0.7004 & 0.0764 \\
\hline
\end{tabular}

As there is no extensive range of statistics for the loss in value of electrified vehicles, within this paper it is assumed that the factors of the ICEV with a diesel engine can also be applied to the BEV and the PHEV. Given the limited data available for the residual value of vehicles in the Chinese market [18], the same assumptions regarding the salvage costs are made for Germany and China.

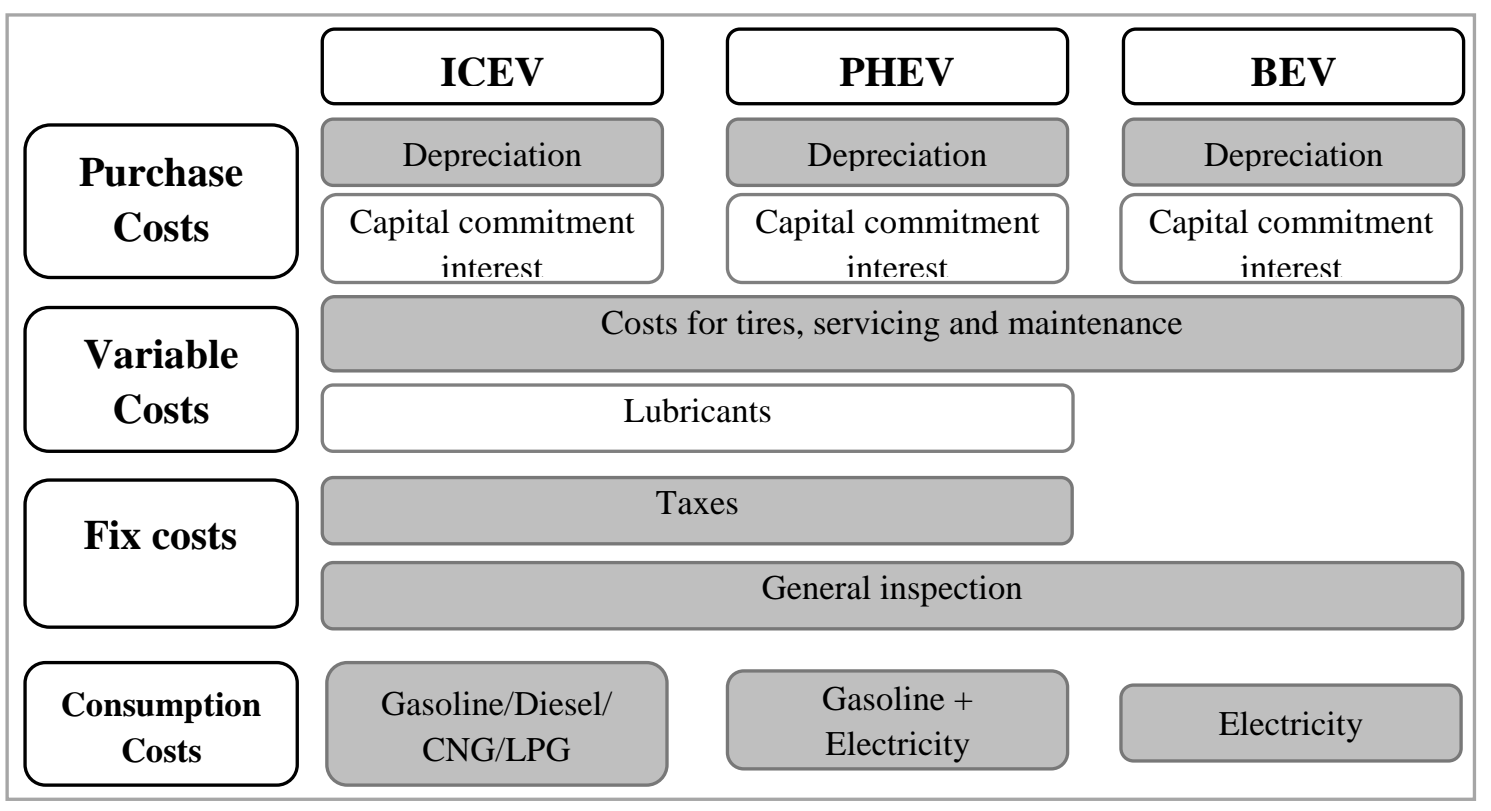

Figure 1. Parameters in TCO Model [29].

The purchase price covers the sales price and additional costs as registration fees and taxes. In this context, the sales prices for alternative drivetrain vehicles are calculated based on a conventional reference vehicle. The detailed calculation is described and verified for German as well as for Chinese vehicles in $[2,13]$. The purchase price for the Chinese TCO model is adjusted to the countries framework conditions and therefore a purchase tax of $10 \%$ before value added tax (VAT) and a registration fee of $500 \mathrm{CNY}$ [31] is added. Additionally, the sales price is reduced by subsidies. Subsidies contain national as well as local subsidies, but are only applied to vehicles produced in China. An overview is shown in Table 4 [32]. Electric vehicles produced in China are also exempt from the purchase tax, while the tax still has to be paid for imported EVs. In addition, custom dues of $25 \%$ and a consumption tax between $1 \%$ and $40 \%$ depending on the vehicle's cylinder capacity are charged for imported vehicles.

The Operation Tax of Vehicle and Ship is calculated according to the engine displacement and differs between provinces. For a subcompact car with an engine displacement between 1.01 and 1.61, a yearly tax rate of 420 CNY has to be paid in Beijing [31]. EVs are also exempt from this tax [32]. Insurance costs are calculated based on the sales price $\mathrm{P}_{-}$MSRP without subsidies. The compulsory accident liability insurance amounts to a yearly rate of $950 \mathrm{CNY}$ for passenger vehicles with less than six seats [31]. 
An additional optional commercial insurance is provided containing a third party liability insurance, damage insurance, glass insurance, passenger insurance, vehicle scratch insurance. With a coverage of $100000 \mathrm{CNY}$, the overall insurance costs can be summarised to

$$
C_{\text {insurance }}=2647.2+P_{M S R P} * 2.0566 \% \text {. }
$$

Maintenance costs in China are set to an average of $500 \mathrm{CNY} / 5000 \mathrm{~km}$ [21]. For variable and fix costs in Germany, [2] is taken into account.

Table 4. Subsidies for private vehicles in China 2015 [32].

\begin{tabular}{|c|c|c|c|}
\hline Region & Criteria* & PHEV[CNY] & $\mathrm{BEV}[\mathrm{CNY}]$ \\
\hline \multirow[t]{4}{*}{ Nationwide } & $R \geq 50 \mathrm{~km}$ & 35000 & \\
\hline & $80 \mathrm{~km} \leq R<150 \mathrm{~km}$ & & 35000 \\
\hline & $150 \mathrm{~km} \leq R<250 \mathrm{~km}$ & & 50000 \\
\hline & $R \geq 250 \mathrm{~km}$ & & 60000 \\
\hline Beijing & Battery capacity & $\begin{array}{l}3000 / \mathrm{kWh} \\
(\max : 50000)\end{array}$ & $\begin{array}{l}3000 / \mathrm{kWh} \\
(\max : 60000)\end{array}$ \\
\hline Shanghai & Vehicle unit & 30 000/vehicle & 40 000/vehicle \\
\hline Changchun & Vehicle price & $\begin{array}{l}20 \% \text { of vehicle price } \\
\text { (max: } 40000 \text { ) }\end{array}$ & $\begin{array}{l}20 \% \text { of vehicle } \\
\text { price (max: } 45000)\end{array}$ \\
\hline
\end{tabular}

$* R=$ electrical range in $\mathrm{km}$

\section{RESULTS AND DISCUSSION}

Based on the investigated criteria, the propulsion systems can be evaluated. Furthermore, and due to the same real driving data a cross-national comparison is possible and the effects of different local legislation and country specific frameworks can be analysed.

\section{Consumption}

The simulated consumptions based on the real driving data of all ICEVs and the BEV are 22-24\% higher than in the NEDC. In contrast, the determined fuel consumption of the PHEV is $15 \%$ lower than in the NEDC, even though the energy consumption is $52 \%$ higher. The reason for that is the greater electrically driven distance. Based on the consumptions and prices for fuel or electricity, the consumption costs for the conurbation driving data can be determined as shown in Figure 2.

In Germany as well as in China, the consumption costs of an ICEV with a gasoline engine are the highest. Contrastingly, the battery electric vehicle has the lowest consumption costs in China, while in Germany the alternative fuel vehicles are most favourable regarding these costs. The average German fuel and electricity costs of the PHEV are between these of both conventional ICEV. In China, the costs of the PHEV are a bit lower as compared to the vehicle with diesel engine. 


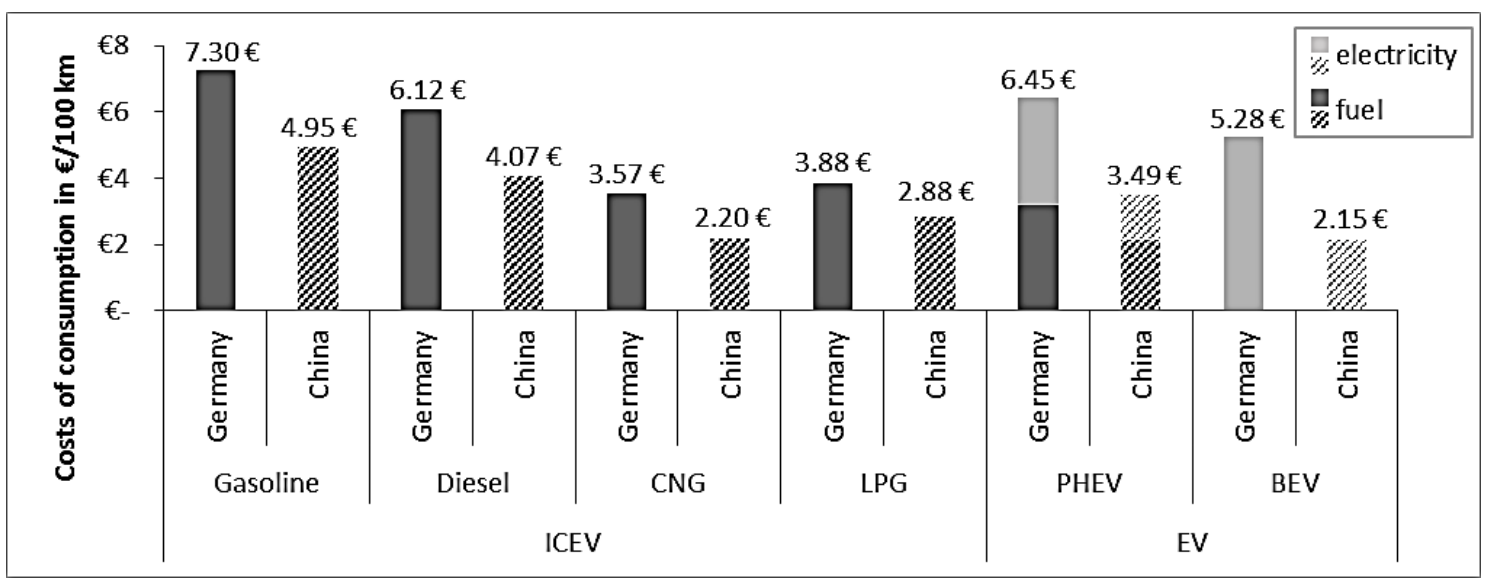

Figure 2. Costs of consumption in $€ / 100 \mathrm{~km}$ for Germany and China [13].

\section{Emissions}

On the basis of the simulated absolute consumption data derived from the real world driving pattern, the $\mathrm{CO}_{2}$-emissions per $\mathrm{km}$ are calculated with the WTW-emission factors (Table 2) for the investigated drive systems for Germany and China. The results are shown in Figure 3. It can be seen that for Germany, emissions can be generally reduced by using alternative drive trains. Thereby the energy mix plays an important role. BEVs using electricity from Germany's energy mix reduce $22 \%$ of the emissions of a gasoline combustion engine driven vehicle, whereas by using the green power mix, a reduction of $82 \%$ may be achieved. For China, electric vehicles are not able to reduce the total emissions. In our study, the PHEV even produces the highest emission values. The emission reduction potential provides vehicles using natural gas, which produce the lowest emissions.

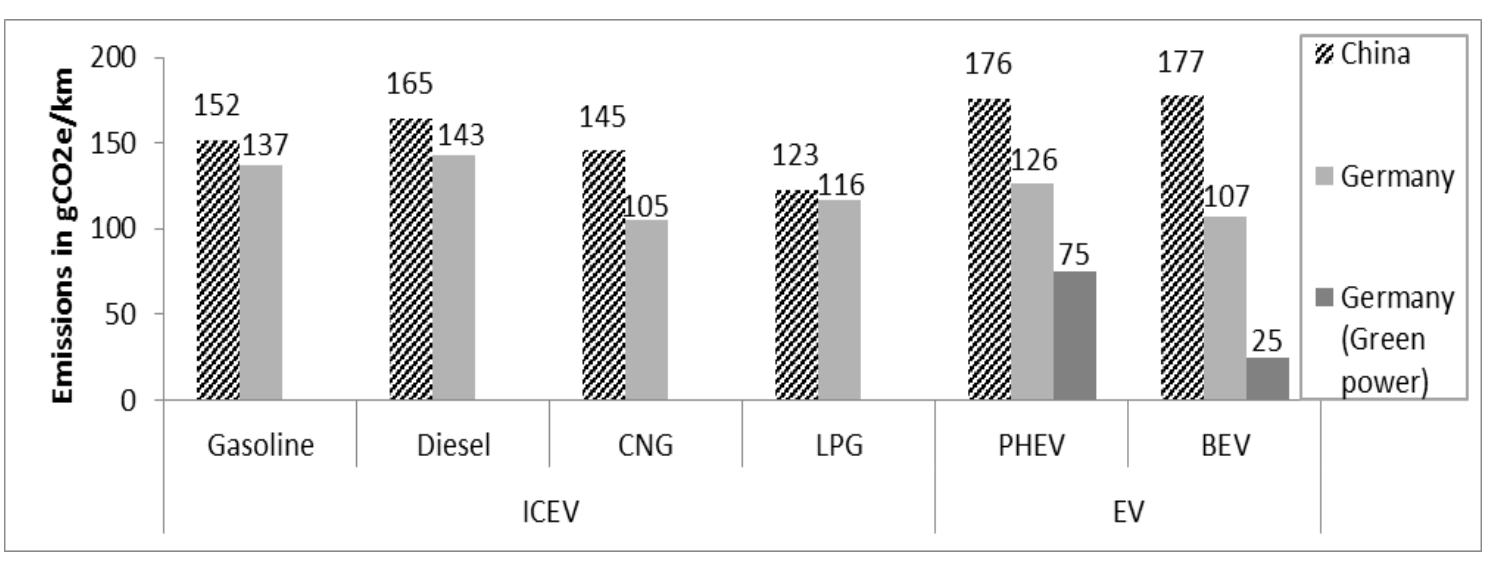

Figure 3. CO2e Emissions per km for Germany and China [13].

According to our estimation, electric vehicles cannot reduce emissions in China as long as the fossil proportion during the generation of electricity is not reduced. However, a local emission reduction in high traffic areas can be achieved due to zero TTW-emissions. A general improvement regarding WTW emissions are gas vehicles.

\section{TCO}


The average yearly Total Costs of Ownership for the reference vehicle are shown in Figure 4 for Germany as well as for China. For the calculation, a holding period of 12 years and a mileage of $25,000 \mathrm{~km}$ per year were assumed. As import costs are considered for China, a higher sales price and therefore higher purchase costs result compared to Germany. In contrast to Germany, subsidies are provided in China, which is why subsidised electric vehicles are also considered in this study even though imported vehicles are excluded from subsidies by now. Although the purchase cost decrease for a BEV through subsidies achieves $38.5 \%$, an EV is not profitable compared to an ICEV in terms of costs for both countries under the assumed conditions.

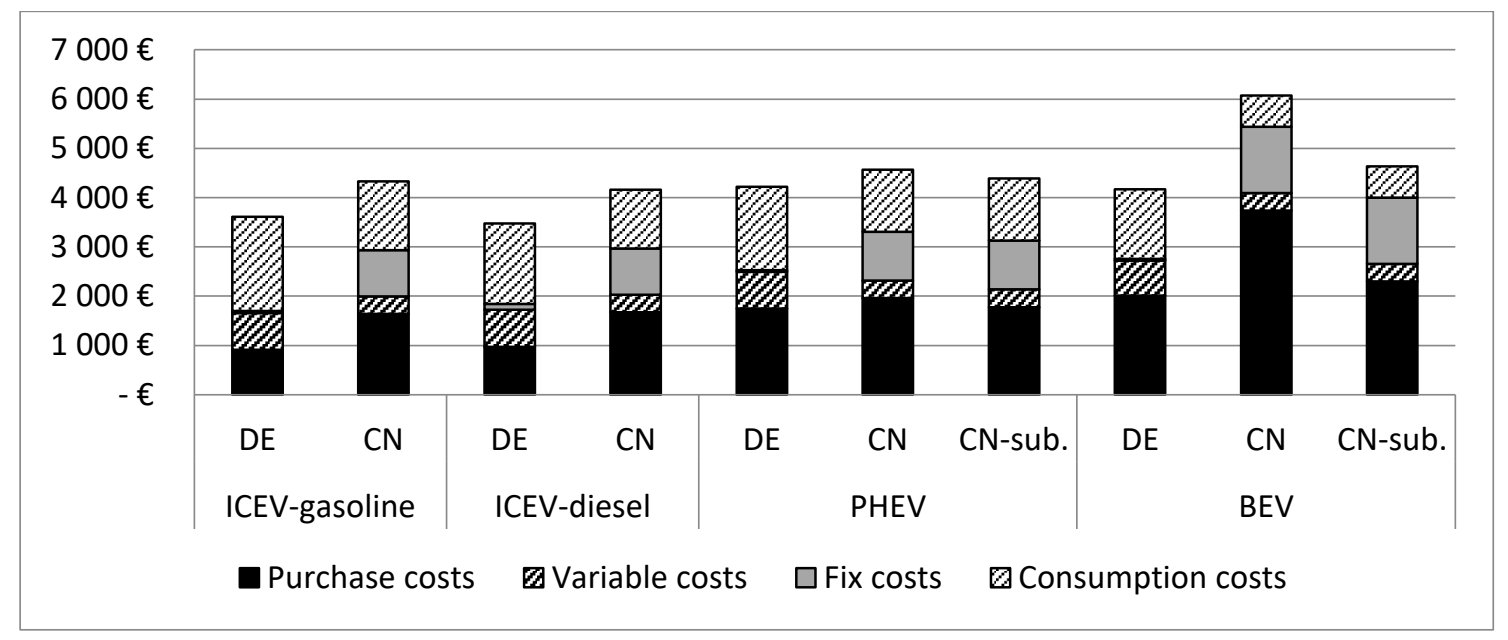

Figure 4. Average costs per year in Germany (DE) and China $(\mathrm{CN})$.

\section{Proposal For A Comparison To Malaysia}

Until now, real world driving data based research on alternative and electrified drivetrains in terms of TCO and emissions is rarely considered for Malaysia. In this study, a first proposal for a comparison is made based on the presented approach.

\section{Consumption}

Under the same conditions assumed for analysing Germany and China, the costs of consumption were derived based on the energy prices adapted for Malaysia, as shown in Table 5. The results in Figure 5 point out that similarly to China, the consumption costs for a PHEV and particularly for the BEV are lower than for a conventional vehicle. The usage of a BEV can reduce gasoline consumption costs by $35 \%$. With a reduction by $37 \%$, the LPG vehicle shows the lowest consumption costs. In total, the consumption costs are much lower compared to Germany and China.

Table 5. Cost per unit of energy for Malaysia [33-35] .

\begin{tabular}{lrr}
\hline & \multicolumn{2}{c}{ Malaysia } \\
\hline Diesel & $0.490 € / 1$ & $2.050 \mathrm{RM} / 1$ \\
Gasoline & $0.490 € / 1$ & $2.050 \mathrm{RM} / 1$ \\
LPG & $0.240 € / 1$ & $1.030 \mathrm{RM} / 1$ \\
Electricity & $0.090 € / \mathrm{kWh}$ & $0.360 \mathrm{RM} / \mathrm{kWh}$ \\
\hline
\end{tabular}




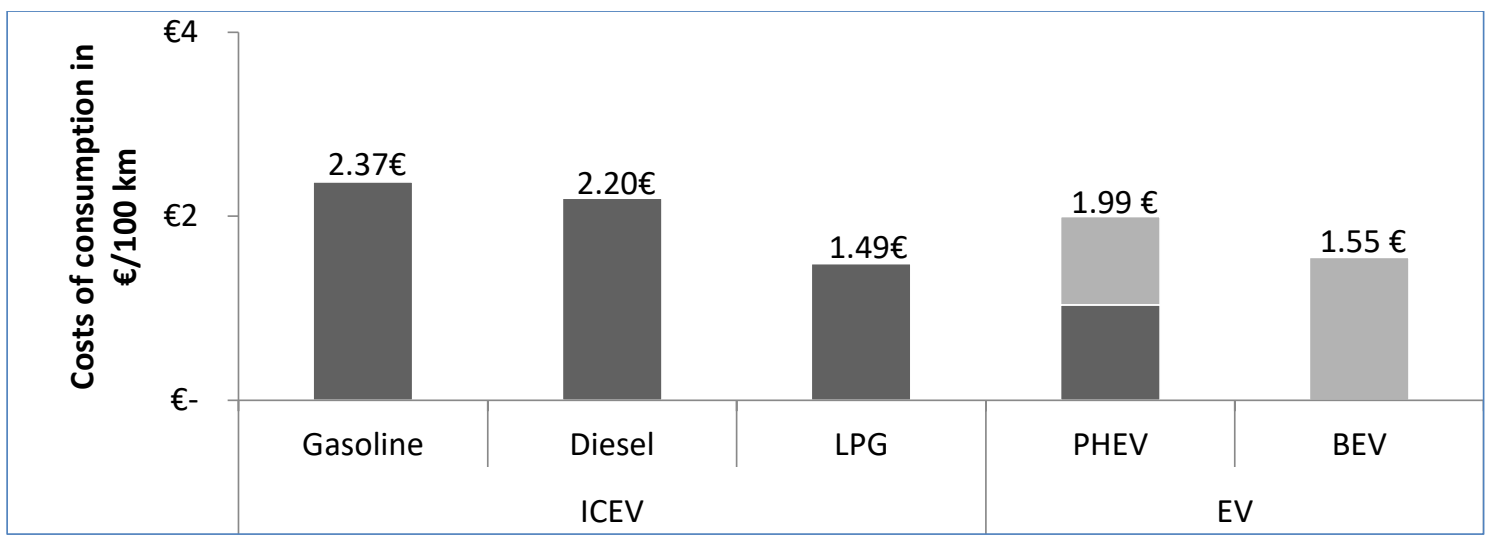

Figure 5. Costs of consumption per $100 \mathrm{~km}$ in the case of Malaysia.

\section{Emissions}

In Malaysia's energy mix, natural gas (40\%) and coal (48\%) are the primary fuels for power generation, while renewable energies account for $7.6 \%$, with a share of $7.4 \%$ hydro [36]. Since Malaysia has renewable energy resources such as biomass and biogas from oil palm wastes, mini hydro, solar and municipal solid wastes, a target of $5.5 \%$ (without hydro) of the energy mix was set in 2002 for 2010 [36]. Although the development of renewable energies is rather slow, some long term energy forecasts estimate a reduction of coal and gas in the energy mix for 2022, even though in near future the fossil fuel rate will grow [36]. Research on WTW-Emissions in Malaysia is still limited. According to the Intergovernmental Panel on Climate Change (IPCC) the Emission factor for electricity in Malaysia was $0.465 \mathrm{kgCO} 2 \mathrm{e} / \mathrm{kWh}$ in 2005 [37], which is much lower than for China and Germany. However, a further development of fossil resources for electricity generation in Malaysia will result in an increased emission of GHG and will hinder Malaysia from achieving its target of reducing carbon emission to the environment, which is why the governmental power section expansion plan has to be reconsidered according to [36].

\section{TCO}

For comparability reasons, the same reference vehicle model as used for analysing Germany and China is necessary. However, the chosen model is not available in Malaysia, which is why the purchase price is calculated assuming it as an imported vehicle in Peninsular Malaysia. Imported vehicles are subjected to excise duties based on the engine displacement listed in Table 6. In addition, an import duty accrues, which amounts to $30 \%$ for fully imported (CBU) and $10 \%$ for locally assembled (CKD) cars [38]. By further adding 6\% Goods and Service Tax (GST), the total CBU retail price is calculated with $146 \%$ of the original retrial price before tax. This amount is verified with imported vehicles available on the market in Malaysia. For the purchase price calculation, the registration fee, inspection and handling fees, number plate fee and HP ownership endorsement fee has to be added in a total sum of $677 \mathrm{RM}$. The variable costs contain tire costs with an average tire price of RM 160 per piece [39]. The yearly road tax differs for private vehicles due to the engine capacity and is currently $20 \mathrm{RM}$ for the reference subcompact vehicle [40], while the calculation of servicing and maintenance costs contains three normal services for RM 200 and one major service for RM 450 per year [39]. Insurance costs are considered with RM 2500 per year. Due to the high variability, toll fares are not considered in this study 
Table 6. Excise duties for imported motor cars (CBU and CKD) in Malaysia.

\begin{tabular}{ll}
\hline Engine Displacement [cc] & Excise Duties (\%) \\
\hline$<1,800$ & 75 \\
$1,800-1,999$ & 80 \\
$2,000-2,499$ & 90 \\
$>2,500$ & 105 \\
\hline
\end{tabular}

Under the same conditions as for Germany and China, the average yearly TCO are estimated (Figure 6). Similar to China, the purchase costs are the major proportion due to the high import fees. Compared to the ICEV, the yearly average purchase costs are extremely high for the PHEV (1500€) and BEV (2000€). In contrast, the BEV can only save $235 €$ due to lower fuel, variable and fix costs a year. The total average TCO of the $\mathrm{BEV}$ and PHEV for Malaysia are higher than for Germany but lower than for China not regarding subsidies. On the other hand, the TCO of the ICEVs are the lowest in Malaysia compared to Germany and China, which mainly results from the low fuel costs.

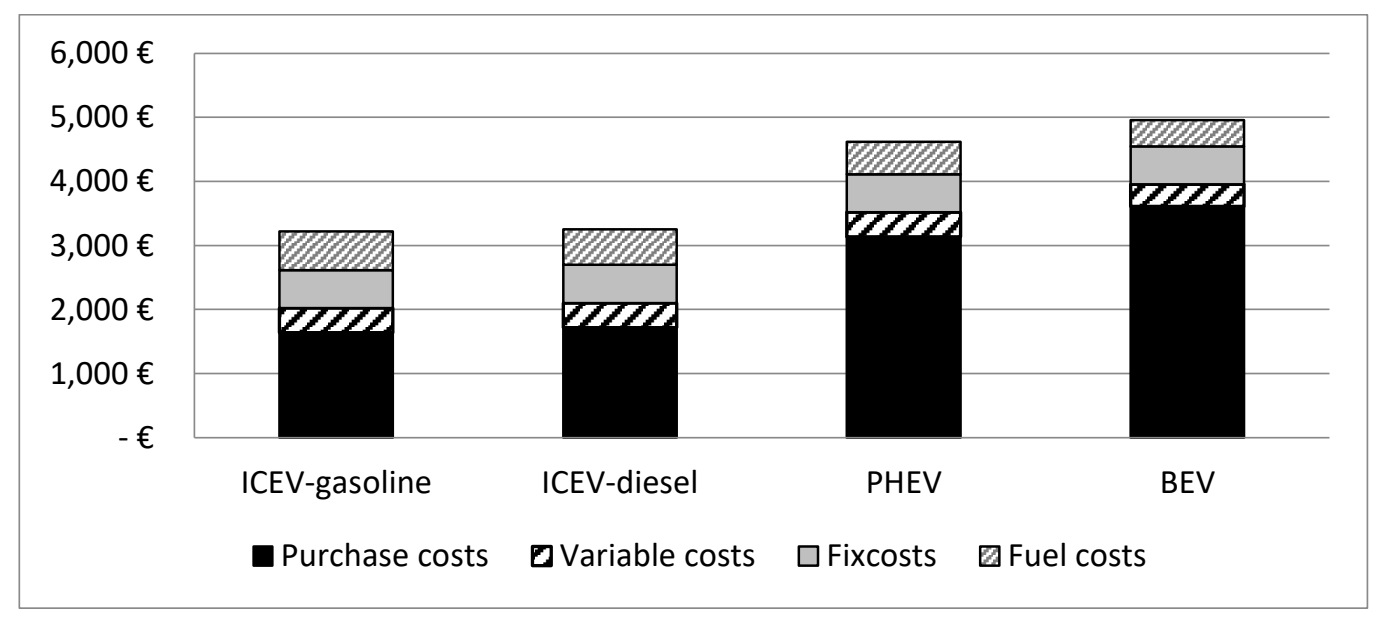

Figure 6. Average costs per year in Malaysia.

\section{CONCLUSIONS}

In this study, a cross-national evaluation of propulsion systems based on real driving data was conducted focusing on consumption, emissions and TCO. The results show that it is important to consider local framework conditions in the calculation of the evaluation and use real world driving data. The evaluation using the recorded driving data shows that while the battery electric and the alternative fuel vehicles are suitable in all considered countries to reduce consumption costs, the position is different in the case of the $\mathrm{CO}_{2}$ emissions. In China, electrified cars cannot reduce the GHG emission because of the currently high fossil proportion during the generation of electricity. In contrast to China, the battery electric cars in Germany could contribute an enormous reduction of emissions, provided that pure green power is used. Gas powered vehicles offer a huge potential in all considered countries. In reviewing the Total Cost of Ownership, the battery electric car is more expensive than the conventional drives, despite its low consumption costs in all analysed countries. Malaysia's fuel costs for gasoline and diesel are much lower than 
in Germany and China and consequently the price difference between the consumption costs of ICEV and BEV in Malaysia is lower. As a result, the TCO of electric vehicles compared to ICEVs are much higher in Malaysia than in China and Germany.

\section{ACKNOWLEDGEMENTS}

The work was partly founded by the German Federal Ministry of Transport and Digital Infrastructure (BMVI), the funding number was 03EM0606C.

\section{REFERENCES}

[1] Schramm D, Koppers M. Das Automobil im Jahr 2025 - Vielfalt der Antriebstechnik. Berlin, Heidelberg: Springer Vieweg; 2014.

[2] Daleske S, Blume S, Schüller M, Koppers M. Vergleich von Antriebskonzepten auf Basis realer Fahrdaten. In: Proff H, editor. 6 Wissenschaftsforum Mobilität Decisions on the Path to Future Mobility. Duisburg, Deutschland: Springer Gabler; 2014.

[3] Ried M, Karspeck T, Jung M, Schramm D. Cost-benefit analysis of plug-in hybrid electric vehicles. ATZ worldwide. 2013;115:44-9.

[4] Ernst C-S, Hackbarth A, Madlener R, Lunz B, Sauer D, Eckstein L. Battery sizing for serial plug-in hybird vehicles: a model-based economic analysis for Germany. In: RWTH Aachen IfFE, Consumer Needs and Behavior, editor.2011.

[5] Mohd Siam MF, Md Isa MH, Borhan N, Sukardi A, Voon WS. Measurement of driver distraction in malaysia's traffic environment: a driving simulator study. Journal of Mechanical Engineering and Sciences. 2015;8:1472-80.

[6] Ismail AR, Abdullah SNA, Abdullah AA, Deros BM. A descriptive analysis of factors contributing to bus drivers' performances while driving: A case study in Malaysia. International Journal of Automotive and Mechanical Engineering. 2015;11:2430-7.

[7] Elkady M, Elmarakbi A, MacIntyre J. Integration of vehicle dynamics control systems with an extendable bumper for collision mitigation. International Journal of Automotive and Mechanical Engineering. 2015;12:2893-913.

[8] Hesse B, Hiesgen G, Koppers M, Schramm D. Einfluss verschiedener Nebenverbraucher auf Elektrofahrzeuge. In: Proff H, Schönharting J, Schramm $\mathrm{D}$, Ziegler J, editors. Zukünftige Entwicklungen in der Mobilität Betriebswirtschaftliche und technische Aspekte: Springer Gabler Verlag; 2012. p. 91-104.

[9] Baha M Al-Alawi and Thomas H. Bradley. Total cost of ownership, payback, and consumer preference modeling of plug-in hybrid electric vehicles. Applied Energy. 2013;103:488-506.

[10] Elektromobilität NP. Zweiter Bericht der Nationalen Plattform Elektromobilität Anhang]. Berlin: Gemeinsame Geschäftsstelle Elektromobilität der Bundesregierung; 2011b.

[11] Ouyang CHHWM. Battery Sizing for Plug-in Hybrid Electric Vehicles in Beijing: A TCO Model Based Analysis. Energies. 2014;7:5374-99.

[12] Tewiele S, Schüller M, Koppers M, Schramm D. Driving pattern analysis of hybrid and electric vehicles in a german conurbation including a drive system evaluation. International Conference on Recent Advances in Automotive Engineering \& Mobility Research Melaka, Malaysia; 2015. 
[13] Schüller M, Tewiele S, Schramm D. Alternative Antriebe und Kraftstoffe zur nachhaltigen Sicherung der Mobilität mit besonderem Fokus auf Ostasien. 7 Wissenschaftsforum Mobilität - National \& International Trends in Mobility. Duisburg: Springer; 2015.

[14] F. Ahmad SAM, H. Zamzuri, H. Jamaluddin, K. Hudha and M. Short. modelling and validation of the vehicle longitudinal model International Journal of Automotive and Mechanical Engineering. 2014;10:2042-56.

[15] ADAC. Kraftstoffpreise in Deutschland. 2015.

[16] Reichert C, Müller K, Bruckmann T. Internal force-based impedance control for cable-driven parallel robots. In: Ceccarelli M, Glazunov VA, editors. CISMIFToMM Symposium on Theory and Practice of Robots and Manipulators. Moscow: Springer; 2014. p. 435-43.

[17] ADAC (Allgemeiner Deutscher Automobil-Club). Retrived from https://www.adac.de/ dated on May 2017.

[18] Bitauto. Retrived from http://ir.bitauto.com/phoenix.zhtml?c=240892\&p=irolIRHome dated on March 2015.

[19] LPG Prices. Retrived from https://www.mylpg.eu/lpg-prices-across-europe dated on November 2015.

[20] Kochhan R, Fiuchs S, Reuter B, Burda P, Matz S, M. L. An overview of costs for vehicle components, fuels and greenhouse gas emissions. Retrived from https://www.researchgate.net/publication/260339436_An_Overview_of_Costs_f or_Vehicle_Components_Fuels_and_Greenhouse_Gas_Emissions dated on January 2017.

[21] Hao H, Wang M, Zhou Y, Wang H, Ouyang M. Levelized costs of conventional and battery electric vehicles in china: Beijing experiences. Mitigation and Adaption Strategies for Global Change. 2013:1-8.

[22] Earley R, Kang L, An F, Green-Weiskel L. Electric Vehicles in the context of sustainable development in China. Background Paper No 9. Beijing, Los Angeles, New York: The Innovation Center for Energy and Transportation; 2011.

[23] Ou X, Zhang X, Chang S. Scenario analysis on alternative fuel/vehicle for China's future road transport: Life-cycle energy demand and GHG emissions. Energy Policy. 2010;38:3943-56.

[24] Zhou G, Ou X, Zhang X. Development of electric vehicles use in China: A study from the perspective of life-cycle energy consumption and greenhouse gas emissions. Energy Policy 2013;59:875-84.

[25] Schramm D, Koppers M. internal final report of project RUHRAUTOe. Essen: Universität Duisburg-Essen; 2015.

[26] DSLV. Berechnung von Treibhausgasemissionen in Spedition und Logistik, Leitfaden. 2013. p. 28.

[27] Shen W, Han W. Well-to-Wheel Analysis for energy consumption and greenhouse gas emissions of electric vehicles using various thermal power generation technologies in China. SAE-China and FISITA (Eds), Proceedings of the FISITA 2012 World Automotive Congress, Lecture Notes in Electrical Engineering 191. Berlin Heidelberg: Springer-Verlag; 2013. p. 101-15.

[28] Bank W.

[29] Kasten P, Zimmer W. $\mathrm{CO}_{2}$-Minderungspotenziale durch den Einsatz von elektrischen Fahrzeugen in Dienstwagenflotten: Ergebnisbericht im Rahmen des Projektes „Future Fleet“. Öko -Institut e.V.; 2011. 
[30] Pietron K. Potentiale von CNG und LNG als alternative Kraftstoffe für PKW und Nutzfahrzeuge. 7 Wissenschaftsforum 2015 - National \& International Trends in Mobility. Duisburg2015.

[31] Sina. Calculator.

[32] Hao H, Ou X, Du J, Wang H, Ouyang M. China's electric vehicle subsidy scheme: Rationale and impacts. J Energy Policy 2014;73:722-32.

[33] Awani A. Lower Electricity Tariff from March 1 in Peninsular Malaysia. 2015.

[34] Bernama. KPDNKK: LPG price remains at RM26.60. Borneo Post online.

[35] Malaysia PP. Latest Petrol Price in Malaysia. 2015.

[36] Basri NA, Ramli AT, S. AA. Malaysia energy strategy towards sustainability: A panoramic overview of the benefits and challenges. Renewable and Sustainable Energy Reviews. 2015;42:1094-105.

[37] Metz B, Kuijpers L, Solomon S, Andersen SO, Davidson O, Pons J, et al. Safeguarding the Ozone Layer and the Global Climate System: Issues Related to Hydrofluorocarbons and Perfluorocarbons. Cambridge: Cambridge University Press; 2005.

[38] Association MA. Duties and Taxes on Motor Vehicles. 2015.

[39] info KD. 2015.

[40] Hiller M, Hirsch K, Bruckmann T, Brandt T, Schramm D. Common aspects in methods for the design of mechatronic systems-applications in automotive and robotic systems. XII International Symposium on Dynamic Problems of Mechanics (DINAME 2009). Angra dos Reis, Rio de Janeiro, Brasilien; 2009. 